\title{
Icariin and icaritin stimulate the proliferation of SKBr3 cells through the GPER1-mediated modulation of the EGFR-MAPK signaling pathway
}

\author{
HAI-RONG MA ${ }^{1,2}$, JIE WANG ${ }^{3}$, YIU-FAI CHEN ${ }^{4}$, HUA CHEN $^{1,2}$, WEI-SHAN WANG ${ }^{5}$ and HAJI AKBER AISA ${ }^{1,2}$ \\ ${ }^{1}$ The Key Laboratory of Plant Resources and Chemistry of Arid Zone, ${ }^{2}$ The State Key Laboratory Basis \\ of Xinjiang Indigenous Medicinal Plants Resource Utilization, Xinjiang Technical Institute of Physics and Chemistry, \\ Chinese Academy of Sciences, Urumqi 830011; ${ }^{3}$ Key Laboratory of Xinjiang Endemic Phytomedicine Resources, \\ Ministry of Education, College of Pharmacy, Shihezi University, Shihezi 832002, P.R. China; ${ }^{4}$ Vascular Biology \\ and Hypertension Program, Department of Medicine, University of Alabama at Birmingham, Birmingham, \\ AL 35294, USA; ${ }^{5}$ School of Medicine, Shihezi University, Shihezi 832002, P.R. China
}

Received December 9, 2013; Accepted March 27, 2014

DOI: $10.3892 /$ ijmm.2014.1722

\begin{abstract}
Icariin (ICA) and icaritin (ICT), with a similar structure to genistein, are the important bioactive components of the genus Epimedium, and regulate many cellular processes. In the present study, using the estrogen receptor (ER)-negative breast cancer cell line, SKBr3, as a model, we examined the hypothesis that ICA and ICT at low concentrations stimulate SKBr3 cell proliferation in vitro through the functional membrane, $\mathrm{G}$ protein-coupled estrogen receptor 1 (GPER1), mediated by the epithelial growth factor receptor (EGFR)-mitogen-activated protein kinase (MAPK) signaling pathway. MTT assay revealed that ICA and ICT at doses of $1 \mathrm{nM}$ to $1 \mu \mathrm{M}$ markedly stimulated SKBr3 cell proliferation in a dose-dependent manner. The ICAand ICT-stimulated cell growth was completely suppressed by the GPER1 antagonist, G-15, indicating that the ICA- and ICT-stimulated cell proliferation was mediated by GPER1 activation. Semi-quantitative RT-PCR analysis revealed that treatment with ICA and ICT enhanced the transcription of c-fos, a proliferation-related early gene. The ICA- and ICT-stimulated mRNA expression was markedly attenuated by G-15, AG-1478 (an EGFR antagonist) or PD98059 (a MAPK inhibitor). Our data also demonstrated that ICA and ICT increased the phosphorylation of ERK1/2. The ICA- and ICT-stimulated ERK1/2 phosphorylation was blocked by pre-treatment of the cells with G-15 and AG-1478 or PD 98059. Flow cytometric analysis confirmed that the ICA- and ICT-stimulated SKBr3 cell
\end{abstract}

Correspondence to: Dr Haji Akber Aisa, Xinjiang Technical Institute of Physics and Chemistry, Chinese Academy of Sciences, 40 Beijing South Road, Urumqi 830011, Xinjiang, P.R. China E-mail: haji@ms.xjb.ac.cn

Key words: icariin, icaritin, G protein-coupled estrogen receptor 1, cell proliferation, epithelial growth factor receptor-mitogen-activated protein kinase pathway proliferation involved the GPER1-mediated modulation of the EGFR-MAPK signaling pathway. To the best of our knowledge, our current findings demonstrate for the first time that ICA and ICT promote the progression of ER-negative breast cancer through the activation of membrane GPER1.

\section{Introduction}

Over the past decade, a novel estrogen receptor (ER), GPR30, now known as $\mathrm{G}$ protein-coupled estrogen receptor 1 (GPER1), was identified as an orphan seven-transmembrane $\mathrm{G}$ protein-coupled receptor (GPCR) by multiple laboratories (1-3). As a functional membrane receptor, GPER1 is distinct from the classical nuclear ERs, including ER $\alpha$ and ER $\beta$ ). GPER1 mediates rapid non-genomic responses to estrogen stimulation which occur within seconds or minutes, such as cAMP production, calcium mobilization and the activation of intracellular kinases, including mitogen-activated protein kinase (MAPK), phosphoinositide-3-kinase (PI3K), protein kinase A (PKA) and protein kinase $C$ (PKC) (4-6). These responses usually cannot be explained by the classical nuclear ER $\alpha$ and ER $\beta$ signaling pathways, which perform their functions through binding to estrogen response element (ERE) located within the regulatory region of target genes, and usually take hours to days to exert an effect on cells (7). Estrogen, tamoxifen (a selective ER modulator), 4-hydroxytamoxifen (OTH), ICI 172,780 (an antagonist of ER $\alpha$ and ER $\beta$ ) and some phytoestrogens are ligands of GPER1 (8).

Herba Epimedii (Yin Yang Huo) is a traditional Chinese herbal medicine that is widely used in the treatment of impotence, involuntary ejaculation, rheumatism, osteoporosis and bone fractures in China for thousands of years (9). Icariin (ICA) is a prenylated flavonol glycoside isolated from plants in the genus Epimedium, and icaritin (ICT) is a derivative hyroxylated at the 3,7-positions of ICA. Both ICA and ICT are important bioactive components of Herba Epimedii. They exert a number of beneficial cellular effects, including promoting apoptosis, stimulating 
angiogenesis, inducing osteogenic differentiation and upregulating extracellular matrix synthesis (10-12). Furthermore, ICA and ICT are also regarded to be active phytoestrogens, exerting estrogenic/anti-estrogenic effects due to their similar chemical structures to genistein, a well-known phytoestrogen (13). It has been reported that low concentrations of ICT $(0.1 \mathrm{nM}$ to $1 \mu \mathrm{M})$ promote MCF-7 cell growth $(14,15)$, while high concentrations of ICT $(>1 \mu \mathrm{M})$ have been shown to inhibit breast cancer cell proliferation, indicating a diphasic regulatory action of ICT (16). The proliferative effects of ICA and ICT on estrogen-dependent breast cancer cells are mainly due to the activation of nuclear ER $\alpha$ - and ER $\beta$-mediated signaling pathways (17). However, little is known about the interactions between GPER1 and ICA or ICT.

Epidermal growth factor receptor (EGFR) is the prototypical member of the family of transmembrane receptor tyrosine kinases. Increasing evidence suggests that the activation of EGFR is involved in GPER1-mediated multiple downstream events (18-20). Among these events, the GPER1-mediated activation of the EGFR-MAPK pathway plays a pivotal role in estrogen-dependent tumor cell proliferation, including breast, endometrial, ovarian and thyroid cancer (14,21-24).

In the present study, we used an ER $\alpha$ - and ER $\beta$-negative breast cancer cell line $(\mathrm{SKBr} 3)$ as a model to identify the possible mechanisms that ICA and ICT promote breast cancer cell proliferation in a non-genomic GPER1-mediated pathway.

\section{Materials and methods}

Chemicals. ICA was purchased from the Chinese National Institute for Food and Drug Control (Beijing, China). ICT was purchased from Tauto Biotech (Shanghai, China). 17 $\beta$-estradiol (E2), DMSO and 3-(4,5-dimethylthiazol-2-yl)2,5-diphenyltetrazolium bromide (MTT) were purchased from Sigma (St. Louis, MO, USA). G-1 (a GPER1 agonist), AG-1478 (an EGFR inhibitor) and PD98059 (a MAPK inhibitor) were obtained from Cayman Chemical Co. (Ann Arbor, MI, USA). G-15 (a GPER1 antagonist) was purchased from Santa Cruz Biotechnology, Inc. (Santa Cruz, CA, USA). Antibodies against ERK2 or phospho-ERK1/2 were obtained from Boster Biotechnology (Wuhan, China).

Cell culture. SKBr3 breast carcinoma cells were obtained from the Chinese Type Culture Collection, Chinese Academy of Sciences (CAS; Shanghai, China) and were maintained in Dulbecco's modified Eagle's medium (DMEM) with $4.5 \mathrm{~g} / 1$ glucose (high-glucose) and $0.37 \%$ sodium bicarbonate (Gibco, Rockville, MD, USA). In routine culture, the cells were supplemented with $10 \%$ fetal bovine serum (FBS) and $1 \mathrm{X}$ antibiotic mix (1x10 $0^{4} / 1$ penicillin A and $100 \mathrm{mg} / 1$ of streptomycin) and grown at $37^{\circ} \mathrm{C}$ in a humidified atmosphere of $95 \%$ air $/ 5 \% \mathrm{CO}_{2}$. Thee days before the cells were treated, the medium was replaced with phenol-red-free DMEM supplemented with $4.5 \mathrm{~g} / \mathrm{l}$ glucose and $0.37 \%$ sodium bicarbonate (Gibco), supplemented with 5\% charcoal-dextran stripped FBS (CDT-FBS; Gibco) to eliminate endogenous estrogen throughout the whole experimental period.

MTT assay. Cell proliferation assay was determined by MTT colorimetric assay. Briefly, the SKBr3 cells were subcultured on the logarithmic phase supplemented with phenol-red-free high-glucose DMEM with 5\% FBS. The cells were counted and seeded in 96-well culture plates at an initial density of $3 \times 10^{3}$ cells/well and allowed to attach to the plates. After $24 \mathrm{~h}$ of attachment, the culture medium was discarded, and the cells were treated with ICA $(1 \mathrm{nM}$ to $10 \mu \mathrm{M})$, ICT $(1 \mathrm{nM}$ to $10 \mu \mathrm{M})$ or ICA $(1 \mathrm{nM}$ to $10 \mu \mathrm{M})$ with or without $\mathrm{G}-15(20 \mu \mathrm{M})$, and ICT $(1 \mathrm{nM}$ to $10 \mu \mathrm{M})$ with or without $\mathrm{G}-15(20 \mu \mathrm{M})$ in $200 \mu \mathrm{l}$ of phenol red-free high-glucose DMEM with 5\% FBS for $48 \mathrm{~h}$. The media were then removed and replaced with $20 \mu \mathrm{l}$ of MTT $(5 \mathrm{mg} / \mathrm{ml})$ in PBS. The plates were incubated for $4 \mathrm{~h}$ at $37^{\circ} \mathrm{C}$ followed by the addition of $150 \mu 1$ DMSO to dissolve the purple crystals, which are products of the MTT substrates. The absorbance was read on a microplate reader at a wavelength of $570 \mathrm{~nm}$. The proliferation rate was calculated as $\mathrm{PR} \%=$ absorbance of experimental group/absorbance of control group x $100 \%$.

Semi-quantitative RT-PCR analysis. The measurement of c-fos mRNA expression was performed by semi-quantitative RT-PCR analysis. Briefly, the SKBr3 cells in phenol red-free DMEM containing 5\% FBS were cultured in 6-well plates at an initial density of $1 \times 10^{5}$ cells/plate. When the cells reached reached $70 \%$ confluency, they were cultured in phenol red-free DMEM containing 5\% FBS for $24 \mathrm{~h}$. The cells were then treated with E2 $(10 \mathrm{nM})$, ICA $(100 \mathrm{nM})$, or ICT $(100 \mathrm{nM})$ for 15 to 60 min with or without pre-treatment with G-15 $(20 \mu \mathrm{M})$, AG-1478 $(10 \mu \mathrm{M})$, or PD98059 $(10 \mu \mathrm{M})$ for $1 \mathrm{~h}$. Total cellular RNA was extracted using TRIzol reagent (CWbiotech, Beijing, China). First-strand cDNA was synthesized using a HiFiMMLV cDNA kit (from CWbiotech). PCR was then performed using specific primer pairs. The level of 36B4 housekeeping mRNA was used as an internal control. The primers used were as follows: c-fos forward, 5'-AGAAAAGGAGAATCCGAA GGGAAA-3' and reverse, 5'-ATGATGCTGGGACAGGAA GTC-3'; and 36B4 forward, 5'-CTCAACATCTCCCCCTT CTC-3' and reverse, 5'-CAAATCCCATATCCTCGTCC-3'. The c-fos and 36B4 DNA products were 420 and $408 \mathrm{bp}$, respectively. Band intensity was quantified with ImageJ software (National Institutes of Health). The experiments were repeated at least 3 times.

Western blot analysis. For quantification of the ERK1/2 levels, the SKBr3 cells were serum-starved for $40 \mathrm{~h}$, and were then treated with E2 (10 nM), ICA (100 nM), ICT (100 nM), or G-1 $(10 \mathrm{nM})$ for 0 to $30 \mathrm{~min}$ with or without pre-treatment with G-15 $(20 \mu \mathrm{M})$ or AG-1478 $(10 \mu \mathrm{M})$ for $1 \mathrm{~h}$. The cells were lysed in RIPA buffer and then lysates were separated by SDS-PAGE. Total ERK and phospho-ERK were detected using the anti-ERK2 or anti-phospho-ERK1/2 antibodies (Boster Biotechnology). The chemiluminescent signal was revealed by the enhanced chemiluminescence system (ECL; Pierce Biotechnology, Rockford, IL, USA) and the protein level was detected by exposure to X-ray film. Band intensity was quantified with ImageJ software. Experiments were repeated at least 3 times.

Cell cycle analysis. The SKBr3 cells were seeded in 6-cm culture plates at an initial density of $5 \times 10^{5}$ cells/plate. Twentyfour hours after attachment, the cells were starved with phenol-red-free high-glucose DMEM with $0.5 \%$ FBS for 3 days. 

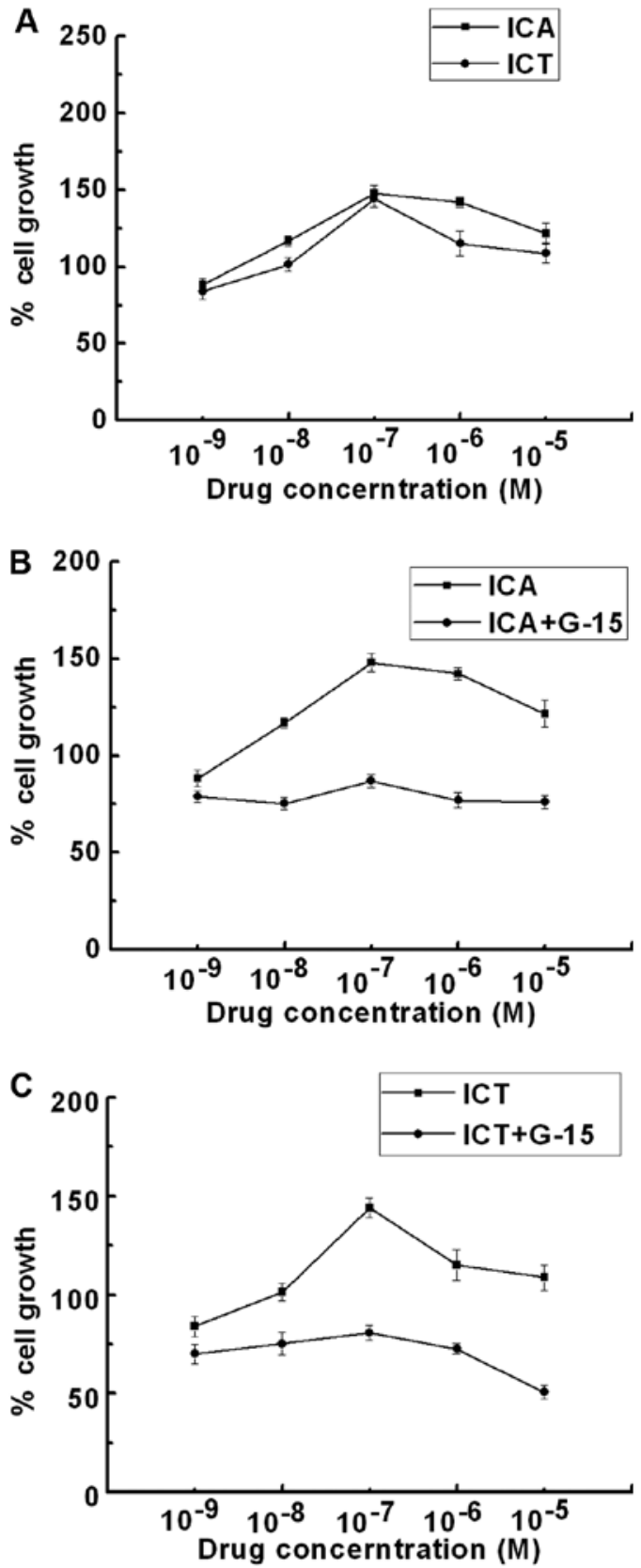

Figure 1. G protein-coupled estrogen receptor 1 (GPER1) mediates icariin (ICA)- and icaritin (ICT)-induced SKBr3 cell proliferation. Cells were treated with (A) ICA $\left(1 \times 10^{-9}\right.$ to $\left.1 \times 10^{-5} \mathrm{M}\right)$ or ICT $\left(1 \times 10^{-9}\right.$ to $\left.1 \times 10^{-5} \mathrm{M}\right)$ (B) ICA $\left(1 \times 10^{-9}\right.$ to $\left.1 \times 10^{-5} \mathrm{M}\right)$ with or without G-15 $(20 \mu \mathrm{M})$, and (C) ICT $\left(1 \times 10^{-9}\right.$ to $\left.1 \times 10^{-5} \mathrm{M}\right)$ with or without $\mathrm{G}-15(20 \mu \mathrm{M})$ in phenol red-free highglucose DMEM medium with 5\% fetal bovine serum (FBS) for $48 \mathrm{~h}$ before counting. The proliferation rate was determined by MTT assay. Results are the means \pm SD from 3 independent experiments.

The cells were then treated with E2 (10 nM), G-1 (10 nM), ICA $(100 \mathrm{nM})$, or ICT $(100 \mathrm{nM})$ with or without pre-treatment with G-15 $(20 \mu \mathrm{M})$, PD98095 $(10 \mu \mathrm{M})$, or AG-1478 $(10 \mu \mathrm{M})$. After $48 \mathrm{~h}$, the cells were harvested and the cell cycle was analyzed as previously described (25). The cell proliferation index (PI) was calculated as $\mathrm{PI} \%=(\mathrm{S}+\mathrm{G} 2 / \mathrm{M}) /(\mathrm{G} 0 / \mathrm{G} 1+\mathrm{S}+\mathrm{G} 2 / \mathrm{M}) \times 100 \%$.

Statistical analysis. The statistical analysis of all data was performed using SPSS 19.0 software. Data are expressed as the means $\pm \mathrm{SD}$, and the level of significance between 2 groups was assessed using a Student's t-test. P values $<0.05$ were considered to indicate statistically significant differences.

\section{Results}

GPERI mediates the ICA or ICT-induced proliferation of $S K B r 3$ cells. Both ICA and ICT stimulated the proliferation of the SKBr3 ER-negative breast cancer cells in a dose-dependent manner (Fig. 1A). The maximal cell proliferative effects were 148 and $144 \%$ at a dose of $1 \times 10^{-7}$ M ICA or ICT, respectively. To determine the involvement of GPER1 in the ICA- or ICT-stimulated proliferation, the SKBr3 cells were co-treated with G-15 (a high-affinity GPER1 antagonist, $20 \mu \mathrm{M}$ ) and ICA $(100 \mathrm{nM})$ or ICT $(100 \mathrm{nM})$. The proliferation of the SKBr3 cells was completely suppressed by G-15 (Fig. 1B and C), suggesting that the ICA- or ICT-stimulated SKBr3 cell proliferation was mediated by the activation of GPER1.

ICA and ICT stimulate c-fos $m R N A$ expression. The proto-gene, c-fos, is an immediate early gene and its expression is rapidly induced by various extracellular mitogens. In order to determine whether ICA or ICT induce c-fos expression, the SKBr3 cells were treated with ICA $(100 \mathrm{nM})$ or ICT $(100 \mathrm{nM})$ for 15, 30 and $60 \mathrm{~min}$. Semi-quantitative RT-PCR analysis was performed to measure c-fos mRNA expression (Fig. 2). The maximal c-fos mRNA expression was detected at 30 min. c-fos mRNA expression was increased by 5.5- and 4.1-fold in response to ICA and ICT treatment, respectively (Fig. 2A and B).

GPERI and EGFR mediate the ICA- and ICT-induced c-fos mRNA expression. To determine whether GPER1 and EGFR are required for the ICA- or ICT-induced c-fos expression, the SKBr3 cells were pre-treated with G-15 (20 $\mu \mathrm{M})$, AG-1478 (an EGFR inhibitor, $10 \mu \mathrm{M})$ for $1 \mathrm{~h}$, and then treated with E2 $(10 \mathrm{nM})$, ICA (100 nM) or ICT (100 nM) for $30 \mathrm{~min}$ (Fig. 3). G-15 and AG-1478 markedly inhibited the E2-, ICA- or ICT-induced c-fos mRNA expression (Fig. 3A-C). These results indicate that ICA and ICT can mimic E2 that interacts with GPER1 and activates downstream EFGR-mediated c-fos gene expression.

Induction of c-fos $m R N A$ expression by ICA and ICT requires ERK1/2 activation. It has been reported that GPER1/EGFRmediated c-fos expression occurs through the activation of the MAPK signaling pathway (23). Thus, we investigated whether ICA or ICT increase the phosphorylation of ERK1/2. ICA or ICT increased ERK1/2 phosphorylation in the SKBr3 cells within $5 \mathrm{~min}$ (Fig. 4A and B). The effects of ICA and ICT were mimicked by G-1 (Fig. 4C). Furthermore, G-15 and AG-1478 significantly blocked the E2-, G-1-, ICA- or ICT-induced ERK1/2 phosphorylation (Fig. 4D and E). In addition, the MAPK inhibitor, PD98059, significantly decreased the E2-, ICA- and the ICT-induced c-fos mRNA expression (Fig. 4F).

ICA and ICT stimulate the proliferation of SKBr3 cells through the GPERI-mediated modulation of the EGFR$M A P K$ signaling pathway. To further confirm that ICA- or ICT-stimulated SKBr3 cell proliferation involves the GPER1mediated activation of the ERFR-MAPK signaling pathway, the SKBr3 cells were starved for 3 days and were then treated with E2 $(10 \mathrm{nM})$, ICA $(100 \mathrm{nM})$ or ICT $(100 \mathrm{nM})$ with or 
Table I. Proliferation of SKBr3 cells at various phases of the cell cycle.

\begin{tabular}{|c|c|c|c|c|}
\hline Drug treatment & G0/G1 (\%) & $\mathrm{S}(\%)$ & $\mathrm{G} 2 / \mathrm{M}(\%)$ & PI $(\%)$ \\
\hline Negative control & $64.1 \pm 3.8$ & $2.4 \pm 0.5$ & $33.6 \pm 0.6$ & 35.9 \\
\hline $\mathrm{E} 2(10 \mathrm{nM})$ & $26.5 \pm 4.2$ & $35.3 \pm 0.5$ & $38.3 \pm 0.9$ & $73.5^{\mathrm{a}}$ \\
\hline ICA (100 nM) & $25.9 \pm 2.7$ & $61.7 \pm 0.3$ & $12.3 \pm 0.8$ & $74.1^{\mathrm{a}}$ \\
\hline ICT (100 nM) & $13.8 \pm 2.6$ & $50.1 \pm 0.6$ & $36.1 \pm 1.1$ & $86.2^{\mathrm{a}}$ \\
\hline $\mathrm{E} 2(10 \mathrm{nM})+\mathrm{G}-15(20 \mu \mathrm{M})$ & $40.6 \pm 3.1$ & $14.9 \pm 0.5$ & $24.5 \pm 0.8$ & 39.4 \\
\hline $\mathrm{ICA}(100 \mathrm{nM})+\mathrm{G}-15(20 \mu \mathrm{M})$ & $42.3 \pm 1.8$ & $19.8 \pm 0.2$ & $18.0 \pm 1.7$ & 37.7 \\
\hline ICT $(100 \mathrm{nM})+\mathrm{G}-15(20 \mu \mathrm{M})$ & $37.7 \pm 2.0$ & $18.8 \pm 0.05$ & $23.5 \pm 0.8$ & 42.3 \\
\hline $\mathrm{E} 2(10 \mathrm{nM})+\mathrm{AG}-1478(10 \mu \mathrm{M})$ & $34.5 \pm 5.2$ & $15.1 \pm 0.6$ & $20.4 \pm 0.6$ & 35.5 \\
\hline ICA $(100 \mathrm{nM})+$ AG-1478 $(10 \mu \mathrm{M})$ & $57.4 \pm 3.2$ & $20.6 \pm 0.2$ & $21.9 \pm 0.6$ & 42.6 \\
\hline $\mathrm{ICT}(100 \mathrm{nM})+\mathrm{AG}-1478(10 \mu \mathrm{M})$ & $66.2 \pm 4.0$ & $9.5 \pm 0.2$ & $24.4 \pm 0.8$ & 33.8 \\
\hline E2 $(10 \mathrm{nM})+$ PD $98059(10 \mu \mathrm{M})$ & $63.4 \pm 2.9$ & $9.6 \pm 0.4$ & $27.1 \pm 0.9$ & 36.6 \\
\hline ICA $(100 \mathrm{nM})+$ PD $98059(10 \mu \mathrm{M})$ & $76.0 \pm 3.5$ & $13.1 \pm 0.2$ & $20.9 \pm 0.5$ & 34.0 \\
\hline ICT $(100 \mathrm{nM})+$ PD $98059(10 \mu \mathrm{M})$ & $56.2 \pm 3.6$ & $15.1 \pm 0.2$ & $28.7 \pm 1.0$ & 43.8 \\
\hline
\end{tabular}

E2, 17 $\beta$-estradiol; ICA, icariin; ICT, icaritin. Results are the means \pm SD. ${ }^{a} \mathrm{p}<0.01$ compared to the negative control (untreated) group.

A

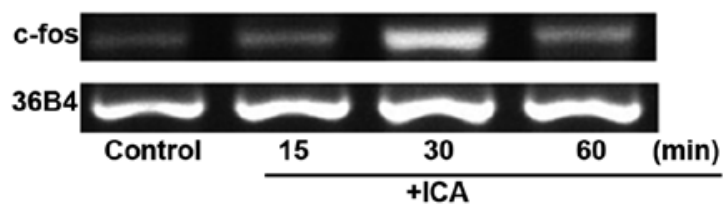

$\mathbf{B}$

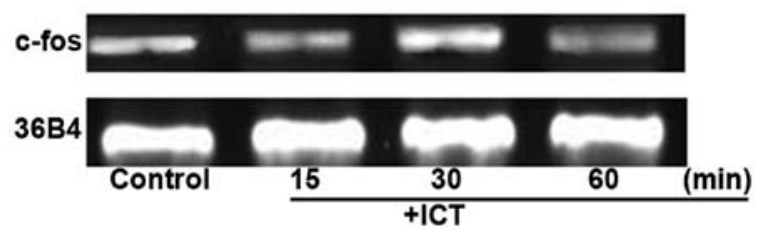

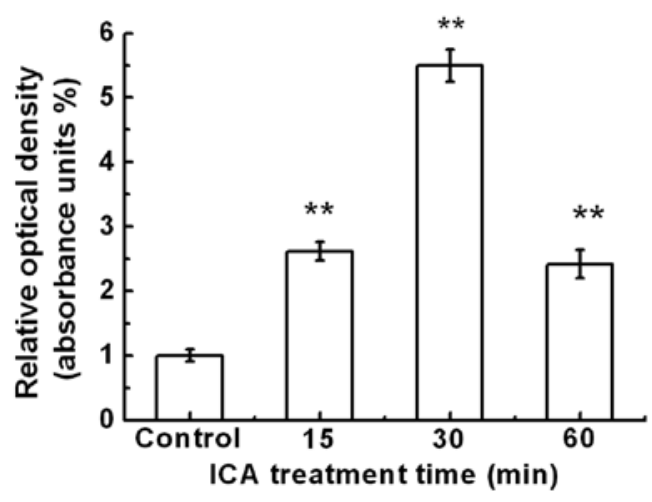

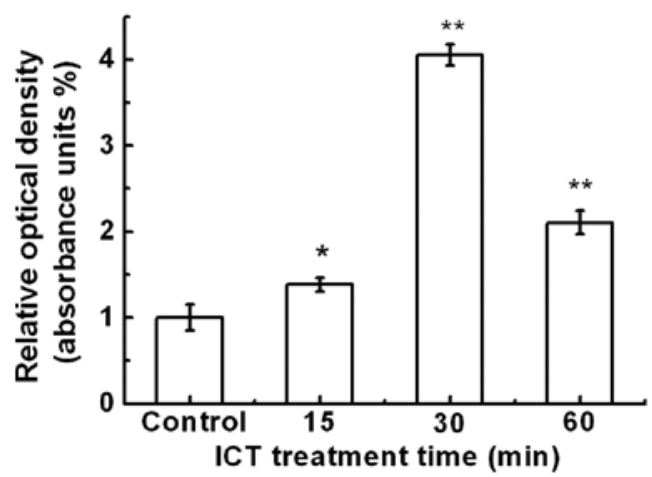

Figure 2. Icariin (ICA) and icaritin (ICT) induce c-fos mRNA expression in SKBr3 cells. Cells were treated with (A) ICA (100 nM), or (B) ICT (100 nM) for 15,30 or 60 min. RT-PCR analysis was performed for the quantification of c-fos mRNA expression. The housekeeping gene, 36B4, was used as an internal control. The right side panels show the meana $\pm \mathrm{SD}$ from 3 independent experiments. $" \mathrm{p}<0.05,{ }^{* *} \mathrm{p}<0.01$ compared to the control (untreated) group.

without pre-treatment with G-15 $(20 \mu \mathrm{M})$, PD $98059(10 \mu \mathrm{M})$ or AG-1478 $(10 \mu \mathrm{M})$ for 2 days. The phase distribution of the cell cycle and proliferation rate was assessed by flow cytometry. We found that, similar to E2, ICA or ICT promoted SKBR3 cell proliferation that was blocked by pre-treatment with G-15, AG-1478 or PD98059. These data suggest that the ICA- and ICT-induced c-fos mRNA expression and cell proliferation of SKBr3 cells requires the activation of the EGFR-MAPK signaling pathway, modulated by GPER1 (Table I).

\section{Discussion}

The present study demonstrates that ICA and ICT stimulate the proliferation of SKBr3 cells, an ER $\alpha$ - and ER $\beta$-negative 
A
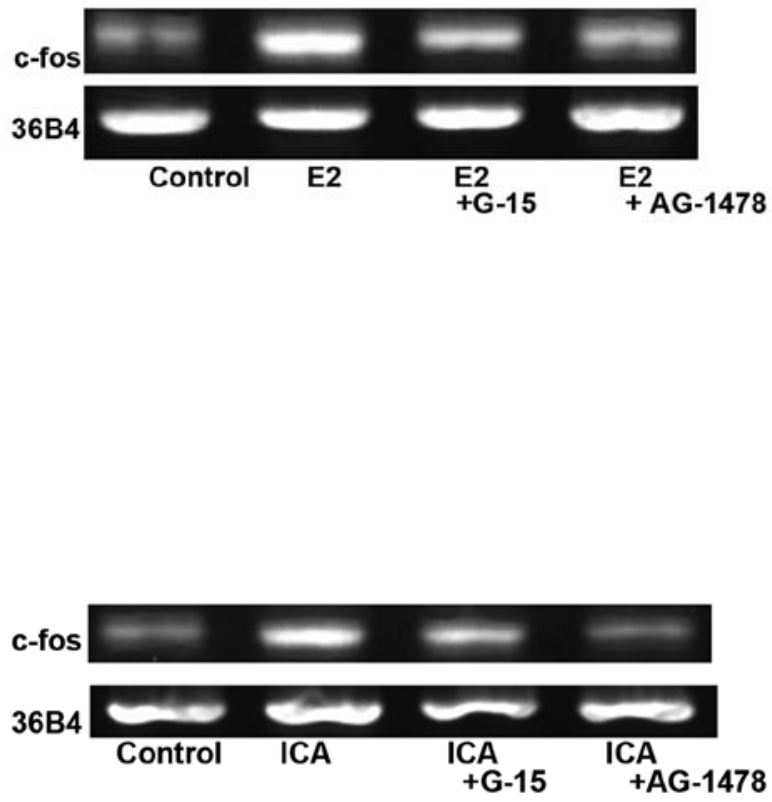

B

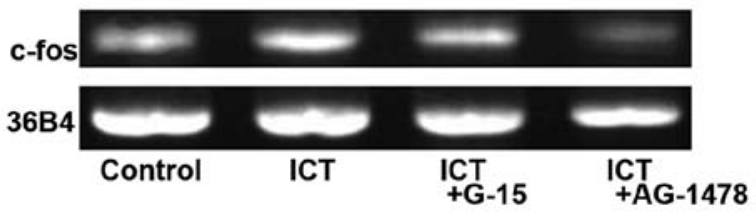

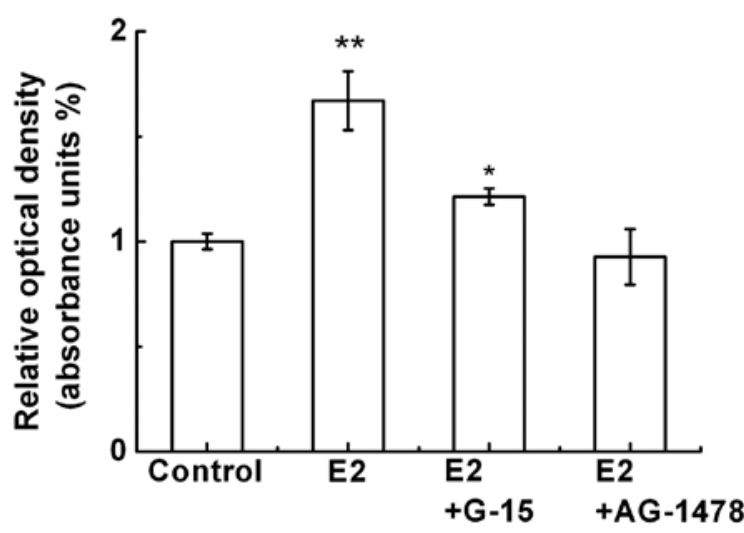
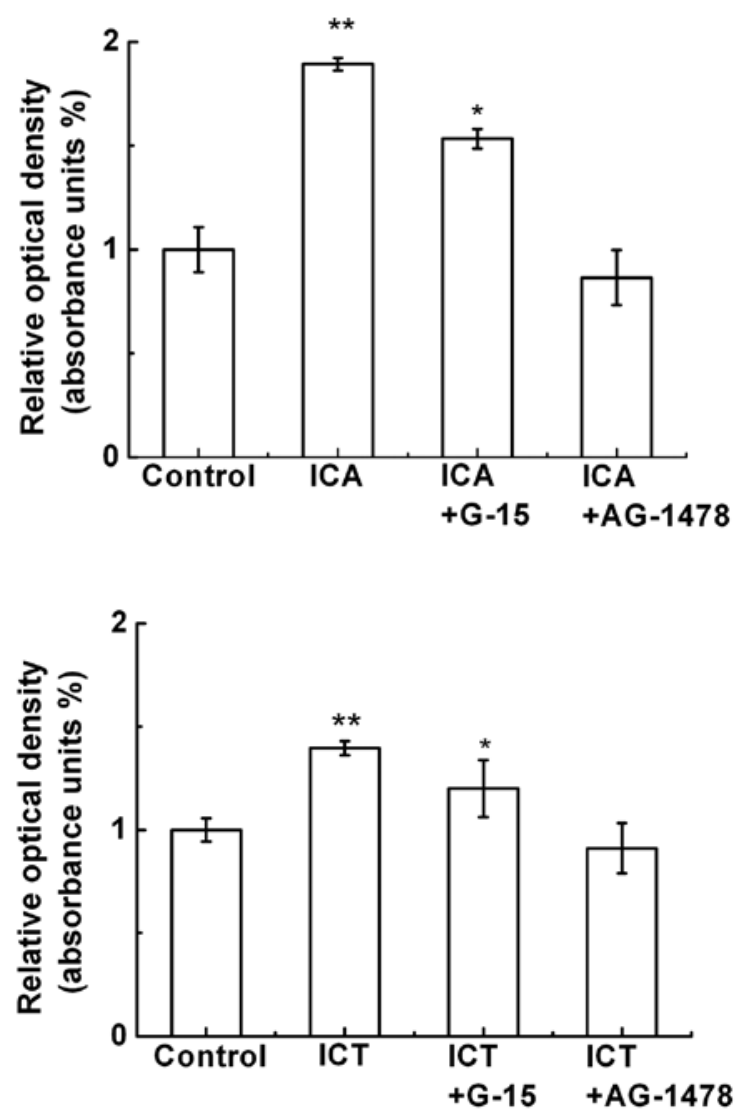

Figure 3. G-15 and AG-1478 inhibit icariin (ICA)- and icaritin (ICT)-induced c-fos mRNA expression in SKBr3 cells. Cells were pre-incubated with G-15 (a GPER1 antagonist, $20 \mu \mathrm{M}$ ) or AG-1478 [epithelial growth factor receptor (EGFR) inhibitor; $10 \mu \mathrm{M}$ ] for $1 \mathrm{~h}$, then treated with (A) $17 \beta$-estradiol (E2; $10 \mu \mathrm{M}$ ), (B) ICA (100 nM), or (C) ICT (100 nM) ICT for $30 \mathrm{~min}$. RT-PCR analysis was performed to quantify c-fos mRNA expression. The housekeeping gene, 36B4, was used as an internal control. The right side panels show the means \pm SD from 3 independent experiments. ${ }^{*} p<0.05,{ }^{* *}$ p $<0.01$ compared to the control (untreated) group.

breast cancer cell line, in vitro. The effects of ICA and ICT on $\mathrm{SKBr} 3$ cell proliferation were mediated by rapid non-genomic GPER1 action, which was associated with the induction of EGFR, MAPK and c-fos expression. This ICA- and ICT-induced SKBr3 cell proliferation was inhibited by inhibitors of GPER1, EGFR and MAPK. These results suggest that ICA and ICT possess the ability to promote breast cancer cell growth through the activation of the EGFR-MAPK signaling pathway, mediated by GPER1.

GPER1 is recognized as an important mediator for promoting breast cancer cell proliferation through rapid non-genomic estrogenic actions. Some phytoestrogens have been proven to be the ligands of GPER1 (8). To the best of our knowledge, our study demonstrates for the first time that a low concentration of ICA and ICT ( $1 \mathrm{nM}$ to $1 \mu \mathrm{M})$ induces SKBr3 cell proliferation through the GPER1-mediated modulation of the MAPK pathway (Fig. 1). Consistent with our findings, genistein and quercetin have been shown to stimulate MCF-7 breast cancer cell growth through a rapid GPER1-mediated action (26). Another phytoestrogen, tectoridin, has also been reported to induce MCF-7 cell growth through the activation of GPRE1-mediated MAPK signaling (27). 
A

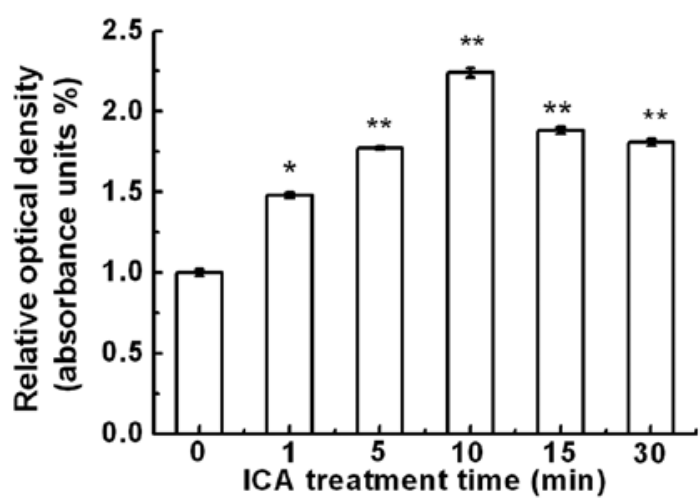

B
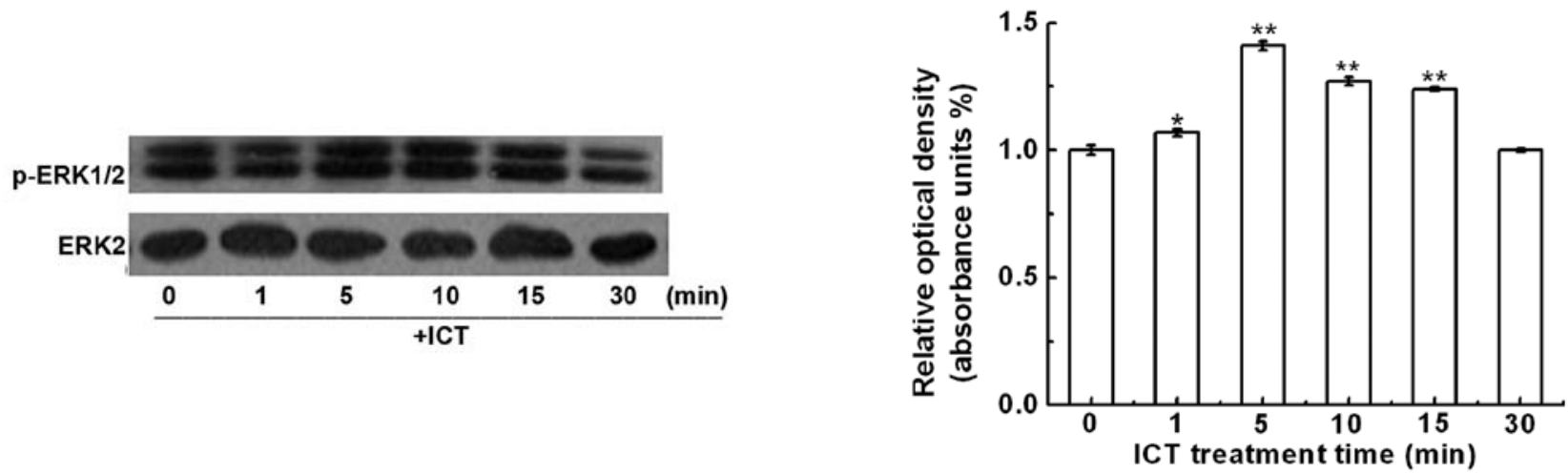

C
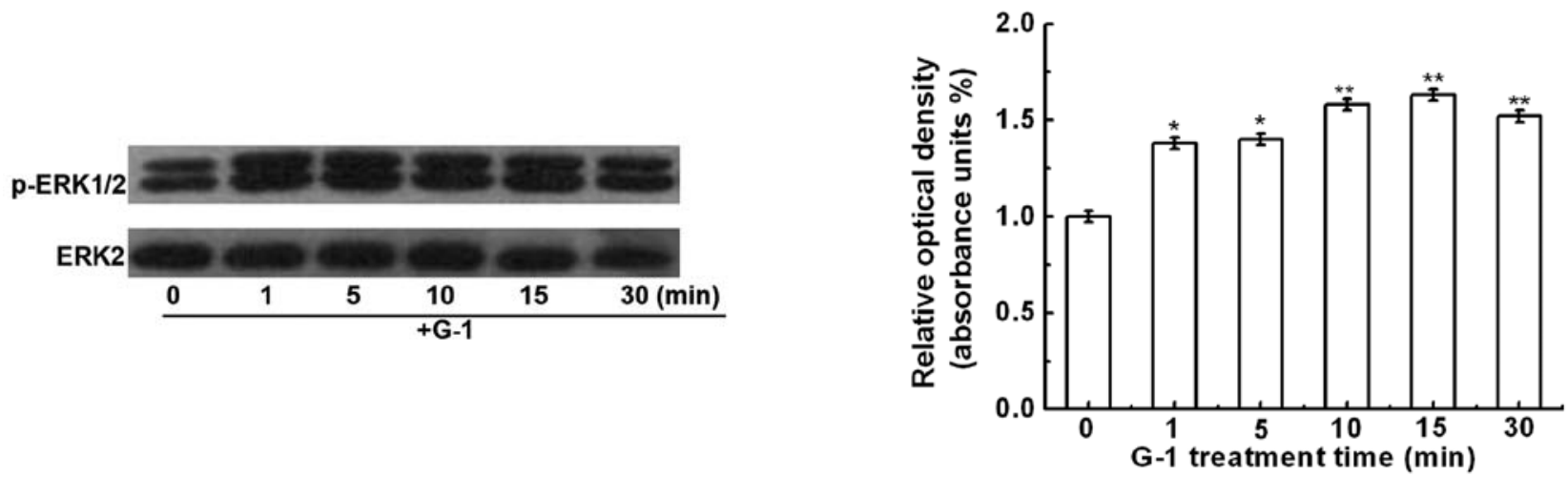

D
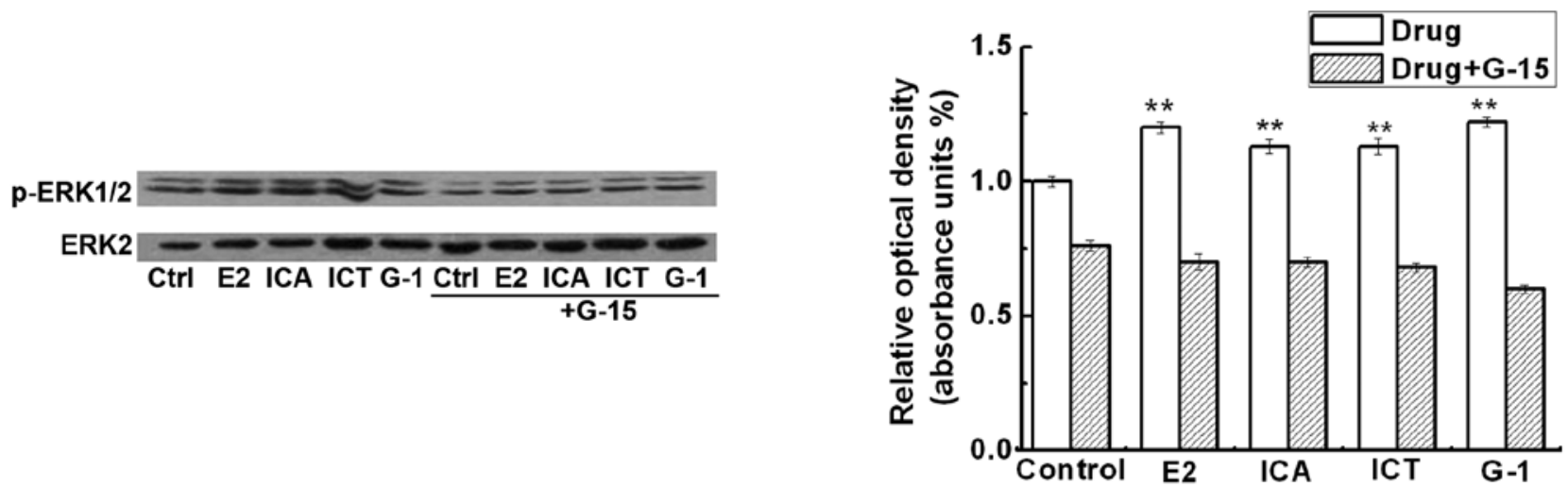

Figure 4. Icariin (ICA) or icaritin (ICT) induces ERK1/2 phosphorylation in SKBr3 cells. SKBr3 cells were serum-starved for $40 \mathrm{~h}$ before being treated for 0 to 30 min with: (A) ICA $(100 \mathrm{nM})$, (B) ICT $100 \mathrm{nM}$ and (C) G-1 (10 nM). (D) SKBr3 cells were pre-treated with G-15 $(20 \mu \mathrm{M})$ for $1 \mathrm{~h}$, and then treated with E2 $(10 \mathrm{nM}), \mathrm{G}-1(10 \mathrm{nM})$, ICA $(100 \mathrm{nM})$ or ICT $(100 \mathrm{nM})$ for $30 \mathrm{~min}$. 
$\mathbf{E}$
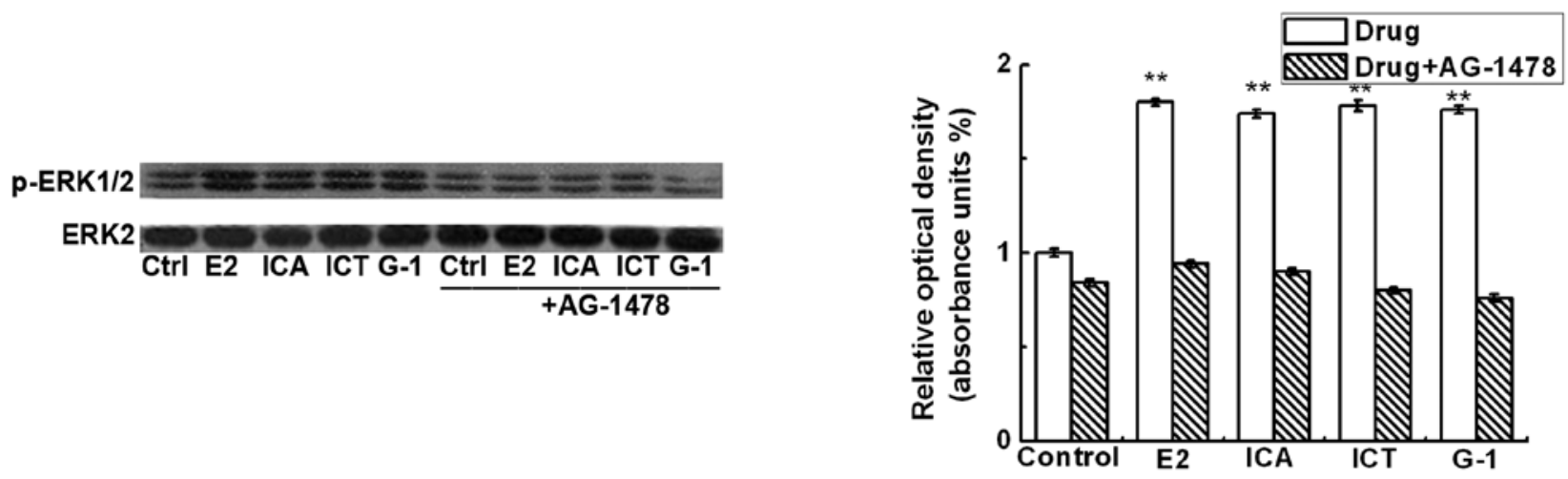

$\mathbf{F}$
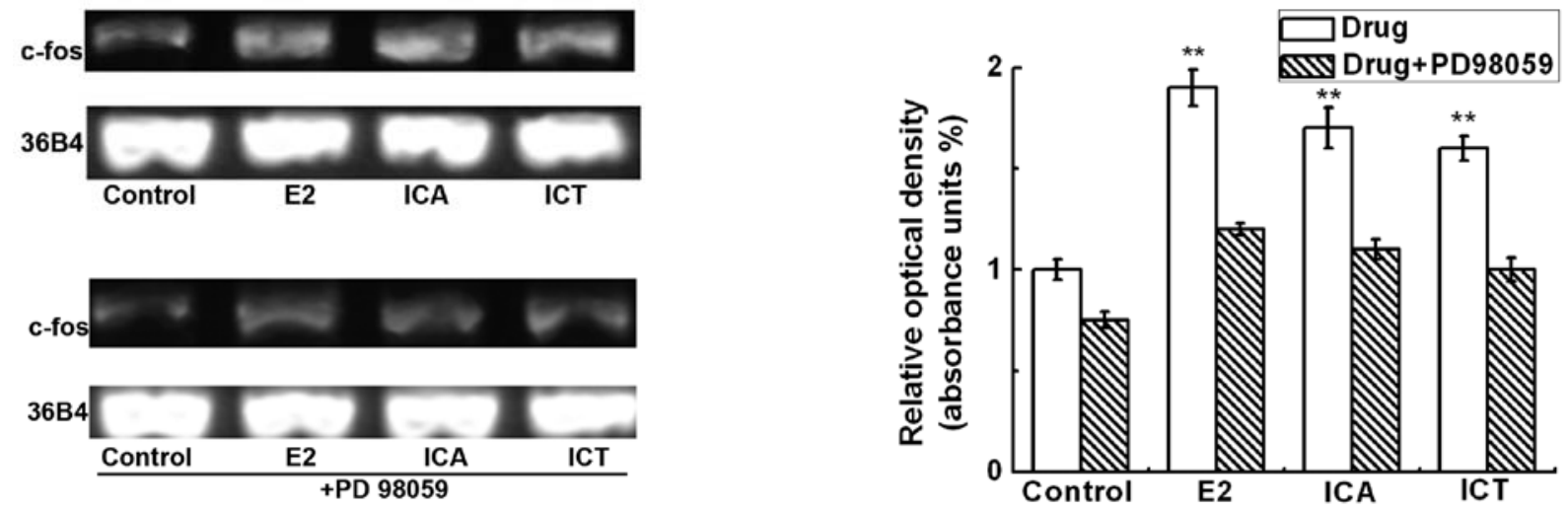

Figure 4. Continued. (E) SKBr3 cells were pre-treated with AG-1478 $(10 \mu \mathrm{M})$ for $1 \mathrm{~h}$, and then treated with E2 $(10 \mathrm{nM})$, G-1 (10 nM), ICA (100 nM) or ICT $(100 \mathrm{nM})$ for $30 \mathrm{~min}$. Cells lysates were used for western blot analysis for total ERK2 and phospho-ERK1/2. ERK2 protein levels were used to normalize ERK1/2 expression. (F) SKBr3 cells were pre-treated with PD98069 $(10 \mu \mathrm{M})$ for $1 \mathrm{~h}$, and then treated with E2 $(10 \mathrm{nM})$, ICA $(100 \mathrm{nM})$ or ICT (100 nM) for $30 \mathrm{~min}$. RT-PCR analysis was performed for quantification of c-fos mRNA expression. The housekeeping gene, 36B4, was used as an internal control. The right side panels show the means \pm SD from 3 independent experiments. ${ }^{* *} \mathrm{p}<0.01$ compared to the control (untreated) group.

Several in vitro studies have demonstrated that EGFRMAPK signaling is involved in GPER1-mediated cell proliferation. Filardo et al demonstrated that E2 activates ERK1/2 through the activation of EGFR by releasing heparinbound epidermal growth factor (EGF) in SKBr3 breast cancer cells (21). Another study also demonstrated that the activation of GPER1 enhances EGF production, which triggers a rapid ERK phosphorylation and c-fos expression in ER-negative SKBr3 and BT20 cells (23). In our study, using SKBr3 cells as a model system, we demonstrated that the GPER1 antagonist, G-15, inhibited ICA- and ICT-induced SKBr3 cell growth, indicating that GPER1 mediated the ICA- and ICT-induced SKBr3 cell proliferation (Fig. 1A and B). Importantly, we found that the ICA- and ICT-induced c-fos mRNA expression was markedly attenuated by the GPER1 antagonist, G-15, and the EGFR antagonist, AG-1478, indicating that the ICA- and ICT-induced c-fos upregulation was mediated through the activation of GPER1 and EGFR (Figs. 2 and 3). Furthermore, we demonstrated that ICA and ICT rapidly stimulated the phosphorylation of ERK1/2 in serum-starved $\mathrm{SkBr} 3$ cells (Fig. 4A and B), which was blocked by pre-treatment with G-15 and AG-1478 (Fig. 4D and E). Consistent with the above results, the MAPK inhibitor, PD98059, blocked c-fos transcription which was induced by ICA and ICT treatment (Fig. 4F). Considering that the proliferation of the $\mathrm{SKBr} 3$ cells also required the EGFR-dependent ERK1/2 activation, we ascertained their roles in the proliferation of $\mathrm{SKBr} 3$ cells by flow cytometry. Indeed, the EGFR antagonist, AG-1478, and the MAPK inhibitor, PD98059, abrogated the response to ICA and ICT (Table I). The above results demonstrated that the ICA- or ICT-stimulated SKBr3 cell proliferation occurred through the GPER1-mediated modulation of the ERFR-MAPK signaling pathway.

Of note, we demonstrated that both ICA and ICT promoted SKBr3 cell proliferation through an ER $\alpha$ - and ER $\beta$-independent, non-genomic pathway, and there was no difference in the proliferative activity between ICA and ICT. However, ICT has been demonstrated to have stronger estrogenic activity than ICA in MCF-7 cells through an ER-dependent pathway due to the steric hindrance produced by glycoside moieties of ICA, which prevents docking to the ER binding site $(14,17)$. A possible explanation for the equal activity of ICA and ICT to promote SKBr3 cell proliferation is that ICA and ICT have a similar binding affinity to GPER1. The presence of 3,7-position glycoside moieties in ICA do not hamper binding to GPER1.

In conclusion, we demonstrate that both ICA and ICT activate the EGFR-MAPK signaling pathway in SKBr3 cells and that this pathway is mediated by the functional membrane, GPER1. GPER1 rapidly transduces a signal from EGFR to ERK1/2, which upregulates c-fos expression and results in 
SKBr3 breast cancer cell proliferation. The precise mechanisms responsible for the ICA or ICT induction of c-fos expression in breast cancer cells require further investigation. To the best of our knowledge, our findings provide new insight into these mechanisms, demonstrating that ICA and ICT induce the progression of ER-negative breast cancer cell growth through the activation of GPER1.

\section{Acknowledgements}

This study was supported in part by grants from the National Natural Science Foundation of China (Grant no. 81102890) and the Joint Funds of the National Natural Science Foundation of China (Grant No. U1203203).

\section{References}

1. Owman C, Blay P, Nilsson C and Lolait SJ: Cloning of human cDNA encoding a novel heptahelix receptor expressed in Burkitt's lymphoma and widely distributed in brain and peripheral tissues. Biochem Bioph Res Co 228: 285-292, 1996.

2. Kuiper GG, Enmark E, Pelto-Huikko M, Nilsson S and Gustafsson JA: Cloning of a novel estrogen receptor expressed in rat prostate and ovary. PNAS 93: 5925-5930, 1996.

3. Carmeci C, Thompson DA, Ring HZ, Francke U and Weigel RJ: Identification of a gene (GPR30) with homology to the G-protein-coupled receptor superfamily associated with estrogen receptor expression in breast cancer. Genomics 45 607-617, 1997.

4. Bouskine A, Nebout M, Bruecker-Davis F, Benahmed M and Fenichel P: Low doses of bisphenol A promote human seminoma cell proliferation by activating PKA and PKG via a membrane G-protein-coupled estrogen receptor. Environ Health Persp 117: 1053-1058, 2009.

5. Filardo EJ: Epidermal growth factor receptor (EGFR) transactivation by estrogen via the G-protein-coupled receptor, GPR30 a novel signaling pathway with potential significance for breast cancer. J Steroid Biochem 80: 231-238, 2002.

6. Revankar CM: A transmembrane intracellular estrogen receptor mediates rapid cell signaling. Science 307: 1625-1630, 2005.

7. Pearce ST and Jordan VC: The biological role of estrogen receptors $\alpha$ and $\beta$ in cancer. Crit Rev Oncol Hematol 50: 3-22, 2004.

8. Prossnitz ER, Sklar LA, Oprea TI and Arterburn JB: GPR30: a novel therapeutic target in estrogen-related disease. Trends Pharmacol Sci 29: 116-123, 2008.

9. Ma H, He X, Yang Y, Li M, Hao D and Jia Z: The genus Epimedium: An ethnopharmacological and phytochemical review. J Ethnopharmacol 134: 519-541, 2011.

10. Huang X, Zhu D and Lou Y: A novel anticancer agent, icaritin, induced cell growth inhibition, G1 arrest and mitochondrial transmembrane potential drop in human prostate carcinoma PC-3 cells. Eur J Pharmacol 564: 26-36, 2007.

11. Chung BH, Kim JD, Kim CK, Kim JH, Won MH, Lee HS, et al: Icariin stimulates angiogenesis by activating the MEK/ERK- and PI3K/Akt/eNOS-dependent signal pathways in human endothelial cells. Biochem Bioph Res Co 376: 404-408, 2008.
12. Zhang L, Zhang X, Li KF, Li DX, Xiao YM, Fan YJ, et al: Icariin promotes extracellular matrix synthesis and gene expression of chondrocytes in vitro. Phytother Res 26: 1385-1392, 2012.

13. Ming LG, Chen KM and Xian CJ: Functions and action mechanisms of flavonoids genistein and icariin in regulating bone remodeling. J Cell Physiol 228: 513-521, 2013.

14. Wang ZQ and Lou YJ. Proliferation-stimulating effects of icaritin and desmethylicaritin in MCF-7 cells. Eur J Pharmacol 504: 147-153, 2004.

15. Yu Y, Yan H, Hu S and Zhang J: Study on the estrogen-like effects of Epimedium extractive. J Xi'an Jiao tong Univ (Med Sci) 30, 373-376, 2009

16. Guo Y,Zhang X,Meng J and Wang ZY: An anticancer agent icaritin induces sustained activation of the extracellular signal-regulated kinase (ERK) pathway and inhibits growth of breast cancer cells. Eur J Pharmacol 658: 114-122, 2011.

17. Ye HY and Lou YJ: Estrogenic effects of two derivatives of icariin on human breast cancer MCF-7 cells. Phytomedicine 12: 735-741, 2005.

18. Levin ER: Bidirectional signaling between the estrogen receptor and the epidermal growth factor receptor. Mol Endocrinol 17: 309-317, 2002.

19. Razandi M: Proximal events in signaling by plasma membrane estrogen receptors. J Biol Chem 278: 2701-2712, 2002.

20. Fujiwara S, Terai Y, Kawaguchi H, Takai M, Yoo S, Tanaka Y, et al: GPR30 regulates the EGFR-Akt cascade and predicts lower survival in patients with ovarian cancer. J Ovarian Res 5: 35, 2012.

21. Filardo EJ, Quinn JA, Bland KI and Frackelton Jr AR: Estrogen-induced activation of Erk-1 and Erk-2 requires the G protein-coupled receptor homolog, GPR30, and occurs via trans-activation of the epidermal growth factor receptor through release of HB-EGF. Mol Endocrinol 14: 1649-1660, 2000.

22. Du GQ, Zhou L, Chen XY, Wan XP and He YY: The $\mathrm{G}$ protein-coupled receptor GPR30 mediates the proliferative and invasive effects induced by hydroxytamoxifen in endometrial cancer cells. Biochem Bioph Res Co 420: 343-349, 2012.

23. Albanito L, Madeo A, Lappano R, Vivacqua A, Rago V, Carpino A, et al: $\mathrm{G}$ protein-coupled receptor 30 (GPR30) mediates gene expression changes and growth response to 17 beta-estradiol and selective GPR30 ligand G-1 in ovarian cancer cells. Cancer Res 67: 1859-1866, 2007.

24. Vivacqua A, Bonofiglio D, Albanito L, Madeo A, Rago V, Carpino A, et al: 17beta-estradiol, genistein, and 4-hydroxytamoxifen induce the proliferation of thyroid cancer cells through the $\mathrm{G}$ protein-coupled receptor GPR30. Mol Pharmacol 70: 1414-1423, 2006.

25. Maggiolini M: The G protein-coupled receptor GPR30 mediates c-fos up-regulation by 17-estradiol and phytoestrogens in breast cancer cells. J Biol Chem 279: 27008-27016, 2004.

26. Ma H, Lu Z, Sun Y, Peng T, Shuai Z, Ma Y, et al: Selection of donor nuclei in somatic cell-mediated gene transfer using a co-transfection method. J Reprod Develop 53: 95-104, 2007.

27. Kang K, Lee SB, Jung SH, Cha KH, Park WD, Sohn YC, et al: Tectoridin, a poor ligand of estrogen receptor $\alpha$, exerts its estrogenic effects via an ERK-dependent pathway. Mol Cells 27: 351-357, 2009. 